\title{
Partial-fistulectomy and Ksharasutra application in the management of complicated fistula-Clinical images
}

\author{
Dr. Shah Bijendra ${ }^{1 *}$ Dr. Dudhamal Tukaram S. $^{2}$ \\ ${ }^{1}$ MS (Ayu) Scholar ${ }^{2}$ Associate Professor \\ Department of Shalya Tantra, Institute for Post Graduate Teaching and Research in Ayurveda \\ (IPGT\&RA), Gujarat Ayurved University, Jamnagar, Gujarat, Pin-361008, India \\ *Corresponding author: email: bijendrashah17@ gmail.com Mob: 09801341818
}

\begin{abstract}
:
No abstract is required as this is clinical images
\end{abstract}

Key words: Bhagandara, Fistula in ano, Partial-fistulectomy, Ksharasutra

\section{Case presentation:}

In the OPD of Shalya tantra a 27 year male patient visited having complaints of swelling in left perianal and pus discharging sinus near anus since last one and half years. Patient reported history that whenever pus was collected, he felt pain and after drainage of pus it was subsided. Patient has no any history of HTN, DM or any cardiovascular disorders and no any significant history of family.

On inspection pus discharging sinus with induration was seen@ 2 and 4 o'clock position in lithotomy posture. On palpation, induration of whole track and cord like structure felt with two external opening@ 2 \& 4 o'clock position. During PR digital examination- two internal opening felt radially @ 3 and 6 o'clock position at mid dentate line. TRUS (TransRectal ultra-sonography) report showed that $6 \mathrm{~cm}$ long fistula with external opening at 4 o clock position and internal opening at $5 \mathrm{o}$ clock position. The $2.8 \mathrm{~cm}$ long branch seen arising from mid part of the fistula with external opening at 2 o clock position. Hence on the basis of clinical findings and TRUS report the case was diagnosed as complicated fistula-inano with two openings. The case was planned for surgery after laboratory investigations which were within normal limit [HB: $12.4 \mathrm{~g} / \mathrm{dL}, \mathrm{RBC}: 6.50 \mathrm{mill} / \mathrm{cmm}$, WBC: $\quad 3700 / \mathrm{cmm}, \quad$ N/L/E/M/B: 50/45/05/03/00 Platelet: 170000/cmm BT: 1.25 min. CT: $3.45 \mathrm{~min}$. RBS: $75 \mathrm{mg} / \mathrm{dl}$ HIV \& HbsAg: Negative]

\section{Procedure of partial fistulectomy (Core} technique) and Ksharasutra application: Under the spinal anesthesia painting draping done and methylene dye was passed through one external opening to identify the course of track during procedure (Figure-2-3). Probing was done (Figure-4) and coring of complete fistulous tract was done up to sphincter (Figure-56). After partial fistulectomy the Ksharasutra was applied in reaming tract (3 to 3 o clock and 4 to 6 o clock) to preserve the sphincter (Figure-8).

Post-operative IV fluids (2 days) antibiotics and analgesic (7 days) and multivitamins (2 months) were given. Along with this sitz bath with Panchavalkal (daily), laxative (at night) and dressing with Jatyadi taila (daily 
once) and Ksharasutra change (weekly once) was done till complete recovery. The post operative progress was well that is wound healing was going normally and cutting of remaining tract was $0.5 \mathrm{~cm}$ weekly as shown in the Figures-9-13. Follow up was done after one and half year and there was no recurrence (Figure-

\section{Clinical Images:}

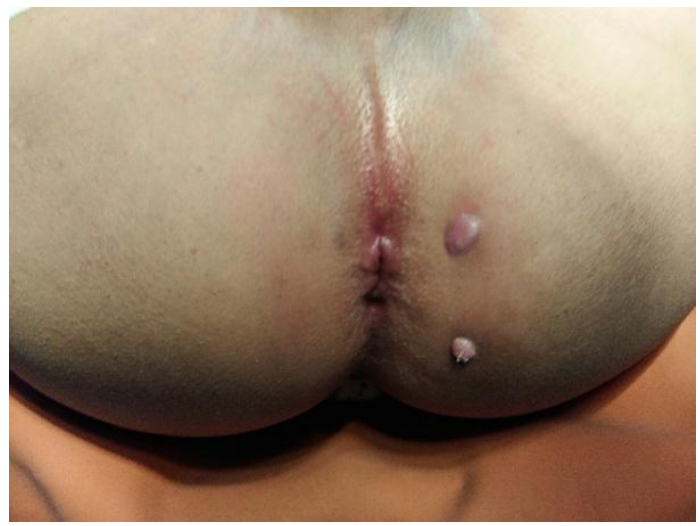

Fig-1: Pre Op. (After spinal anaesthesia)

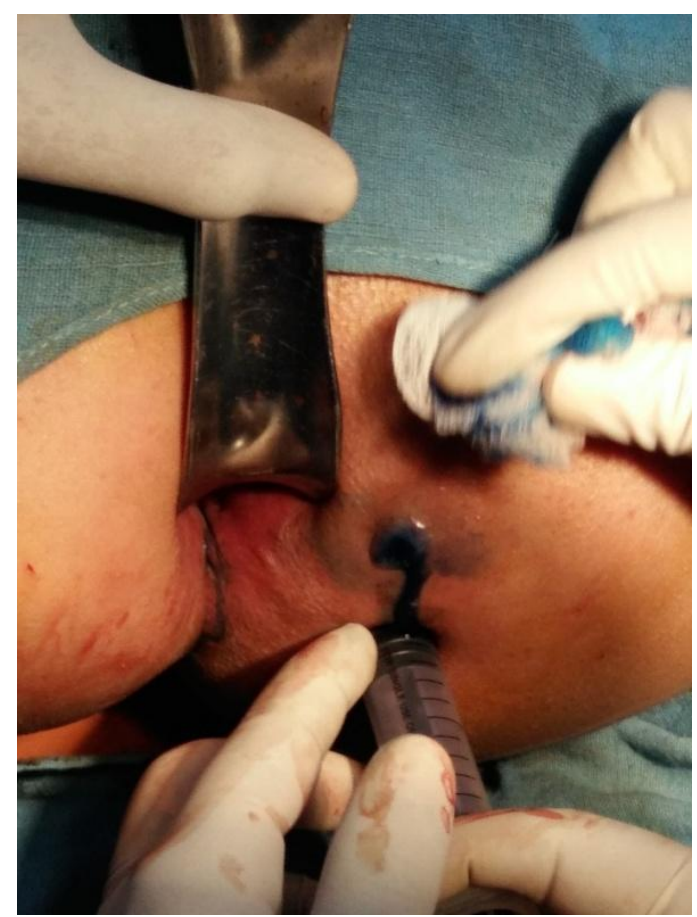

Fig-3: Dye coming from internal and external openings
14). Finally the case was cured completely and patient enjoying his quality of life without any complication and recurrence. Hence this clinical images showed that the integrative approach of partial fistulectomy and Ksharasutra provide early recovery without recurrence.

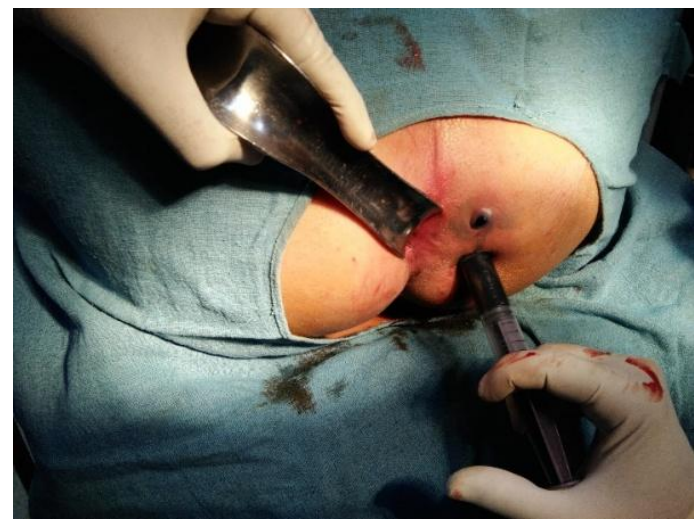

Fig-2: Pushing dye into fistula track

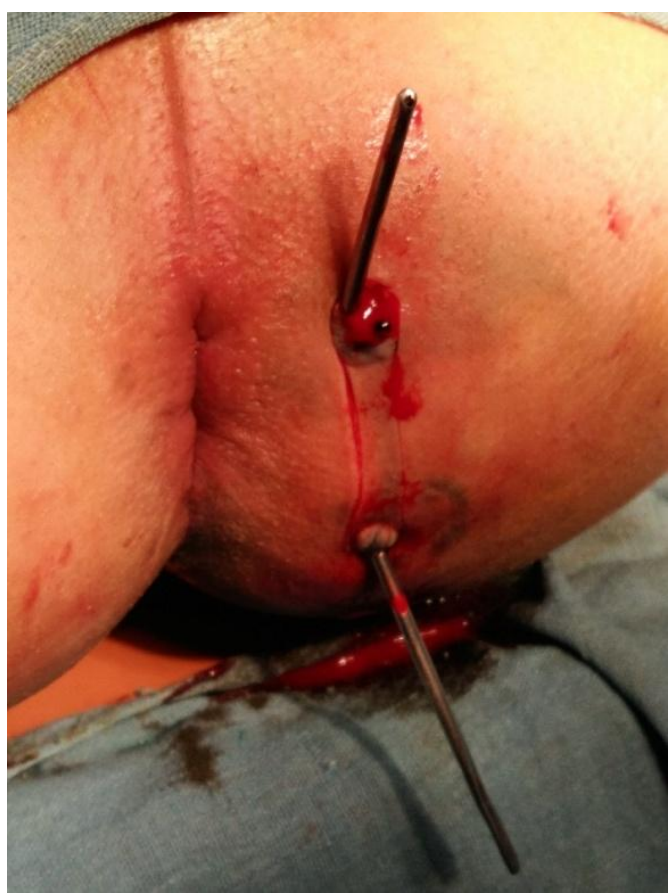

Fig-4: External to external probing during surgery 
INTERNATIONAL JOURNAL OF AYUSH CASE REPORTS (IJA-CARE)

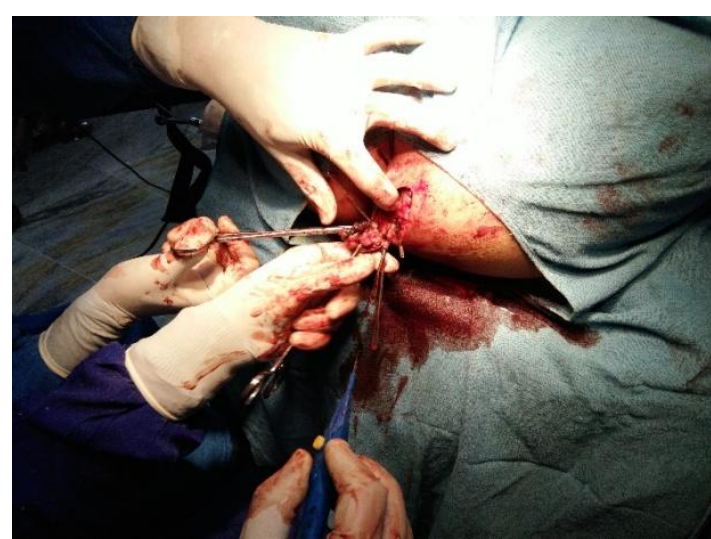

Fig-5: Coring the tract

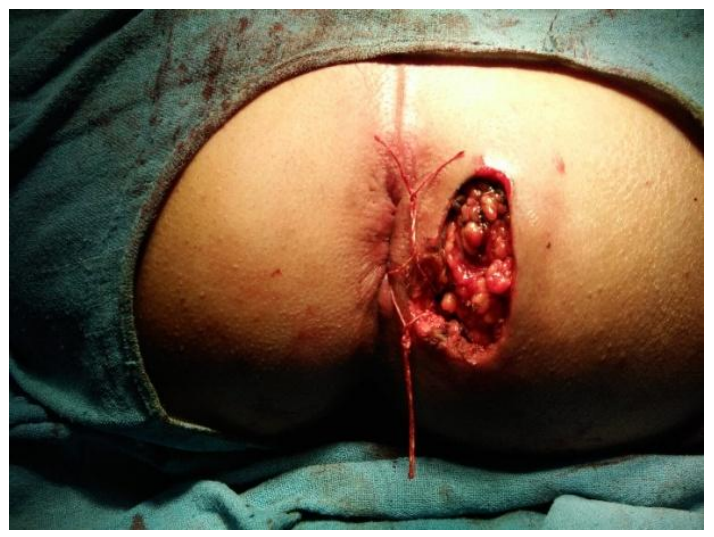

Fig-7: Post-operative on table two Ksarasutra in situ

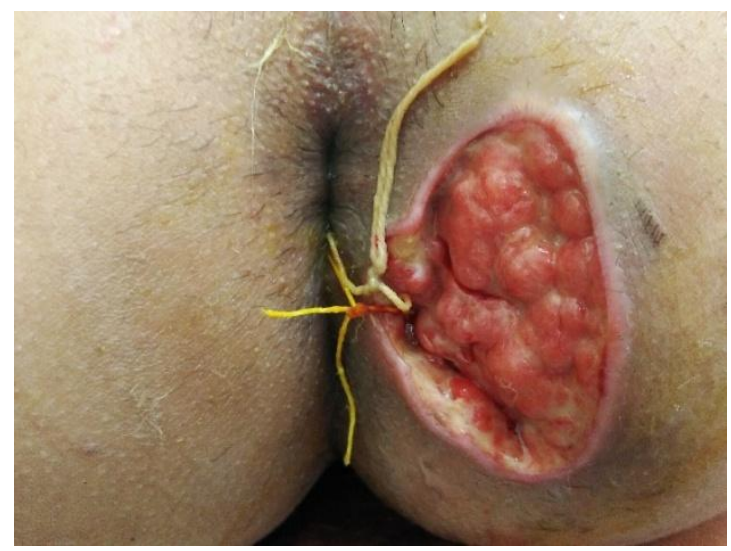

Fig-9: Post-Operative $2^{\text {nd }}$ week healthy fistulectomy wound

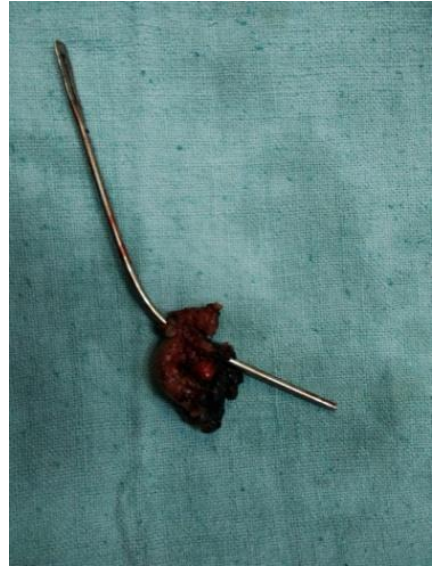

Fig-6: Complete removal of the tract

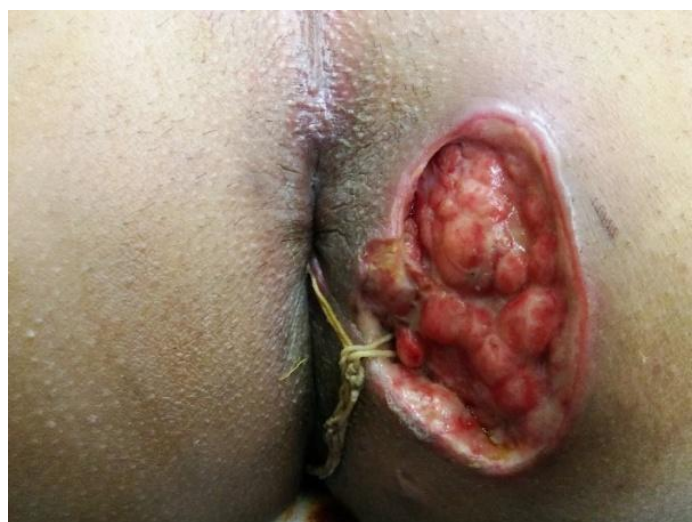

Fig-8: Post-Operative $1^{\text {st }}$ week

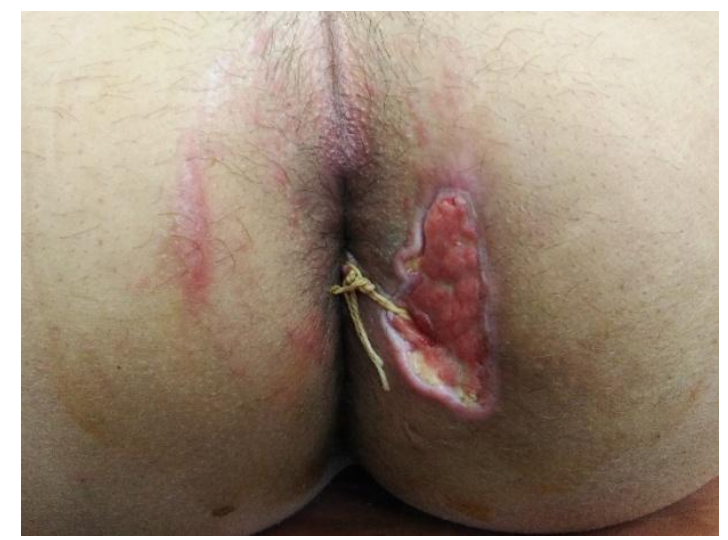

Fig-10: Post-Operative $4^{\text {th }}$ week (healthy granulation) 


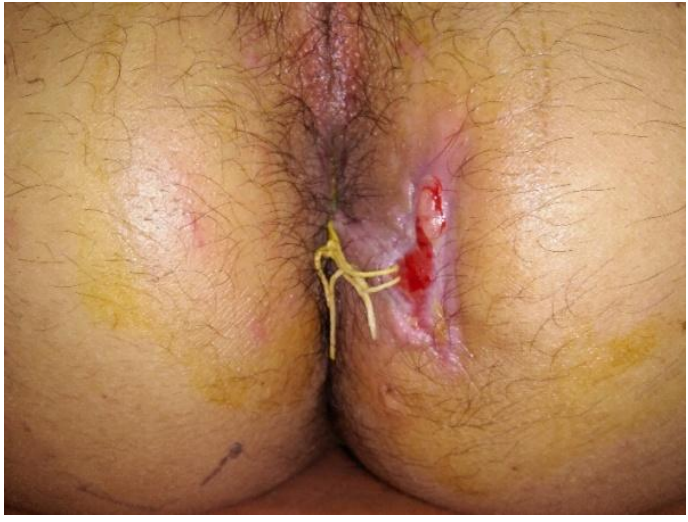

Fig-11: Post-Operative $6^{\text {th }}$ week (healing wound with $K S$ in situ)

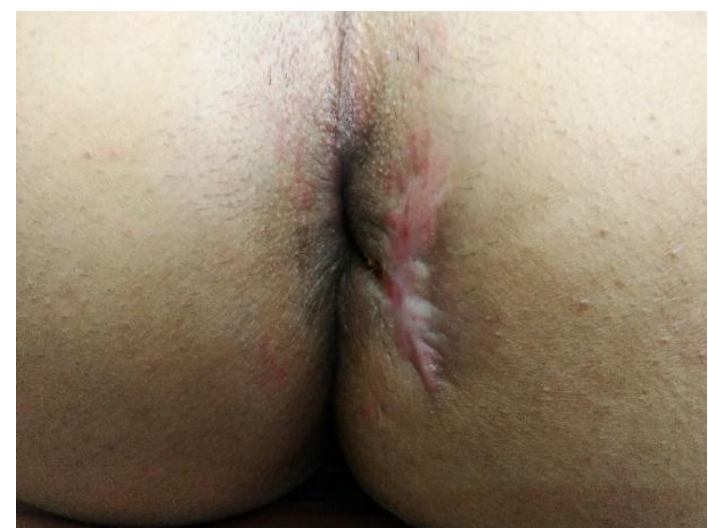

Fig-13: Post-Operative $8^{\text {th }}$ week (healed scar)

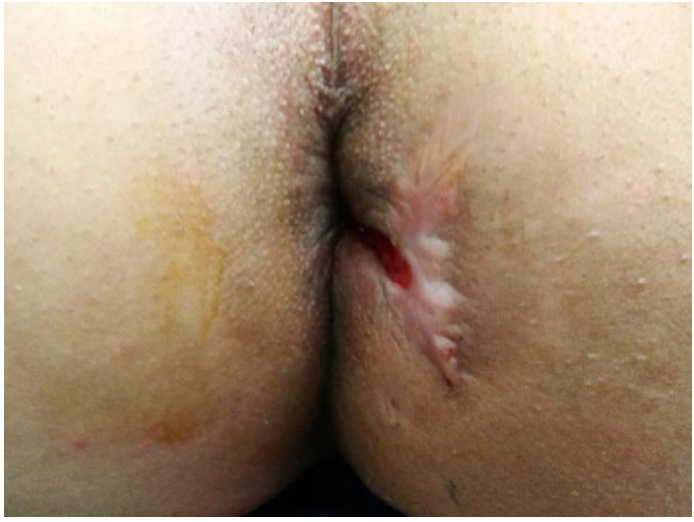

Fig-12: Post-Operative $7^{\text {th }}$ week (Both Ksharasutra cut through)

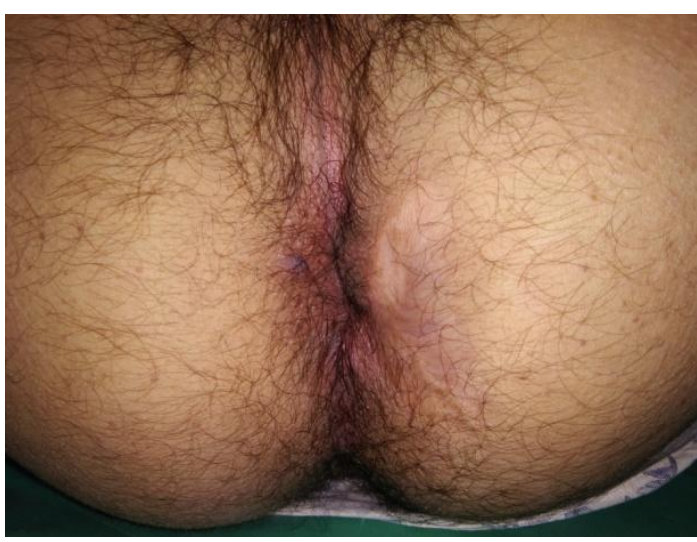

Fig-14: Follow up after one and half year with small scarr

Guarantor: Corresponding author is guarantor of this article and its contents.

Conflict of interest: Author declare that there is no conflict of interest

\section{How to cite this article:}

Shah B, Dudhamal TS. Partial-fistulectomy and Ksharasutra application in the management of complicated fistula - Clinical images. Int. J AYUSH CaRe. 2017;1(1): 32-36 